\title{
INTERACTIONS BETWEEN PUPILS WITH SEVERE MULTIPLE DISABILITY AND TEACHERS
}

\author{
Jiří Kantor \\ Libuše Ludíková \\ Miluše Hutyrová \\ Pavel Svoboda
}

Institute of Special Education Studies, Faculty of Education,

Palacky University, Czech Republic

\begin{abstract}
The paper presents a study (mostly of a quality design) aimed at the teacher-pupil interaction performed at the Institute of Special Education Studies, Palacky University in Olomouc. The data was collected by semi-structured interviews, observation of the educational process and a questionnaire survey. Open, axial and selective coding as well as logic analysis of the responses was used for the data analyses. A synthesis of various data as well as various theoretical backgrounds led to the development of a model for the description of the relationship between the teacher and the pupil with severe mental, physical and communicational disability. The paper includes a description of the categories of this model and their process-based classification into inputs, course and outputs.
\end{abstract}

Keywords: Communication, education, interaction, multiple disability.

\section{Introduction}

The teacher-pupil relationship is considered a key aspect of the educational process, where its quality determines the quality of education (Průcha, 2009). In spite of this fact, the teacher-pupil interaction and the development of their relationship has been insufficiently addressed by Czech professional literature. Particularly in the context of pupils with severe multiple disability there are rare conclusions, mostly based on the teachers' empiric experience. Some studies primarily focused on other topics while the interaction issue was dealt with marginally, e.g. study by Hrebeňárová (2012), Michalík (2012).

In foreign literature (particularly in English speaking countries) many more relevant studies and sources are available. However, it is difficult to generalize these data to be applied in the environment of Czech special schools due to different educational systems and different contexts in which the teacher-pupil interaction takes place. While in most Western countries pupils with severe multiple disability are subject to an inclusive trend, in the Czech Republic these pupils are educated in special schools. For these reasons the interaction process was addressed by one of the IGA project studies called Research of Quality of Life of Individuals with Special Needs carried out at the Institute of Special Education Studies, Palacky University in Olomouc.

The aim of the study was to analyse the inputs, course and outputs of education. We were interested in the categories that are important in relation to the interaction between the teacher and a pupil with severe multiple disability. Covering these categories led to the development of a model for the description 
of the interaction process. The research used mixed methodology of a primary quality-based focus. Data collection was based on 45 semi-structured interviews with teachers, analyses of educational documents (30 verbal evaluations and 30 individual educational plans), observation of the educational process of four pupils and a questionnaire survey aimed at 101 teachers.

Conditions for the selection of teachers into the research sample included a university degree in special education and a minimum of two-year experience with educating pupils with severe multiple disability.

A prerequisite for the inclusion of pupils into the research sample was a combination of severe physical, mental and communication disability.

The data were classified according to the source, converted into text and prepared for a quality-based analysis. The data analysis was performed by means of open, axial and selective coding. Through the open coding the data were divided into categories and subcategories and further to the following eight areas: significance of education and pupil's educational needs, facilitators of teacher-pupil interaction, tools to understand pupils, teacher-pupil communication, physical, mental and social needs of pupils, other statements about pupils (e.g. about their personal qualities), process and methodological aspects of the educational process and teachers' profits, difficult situations and methods of addressing these situations.

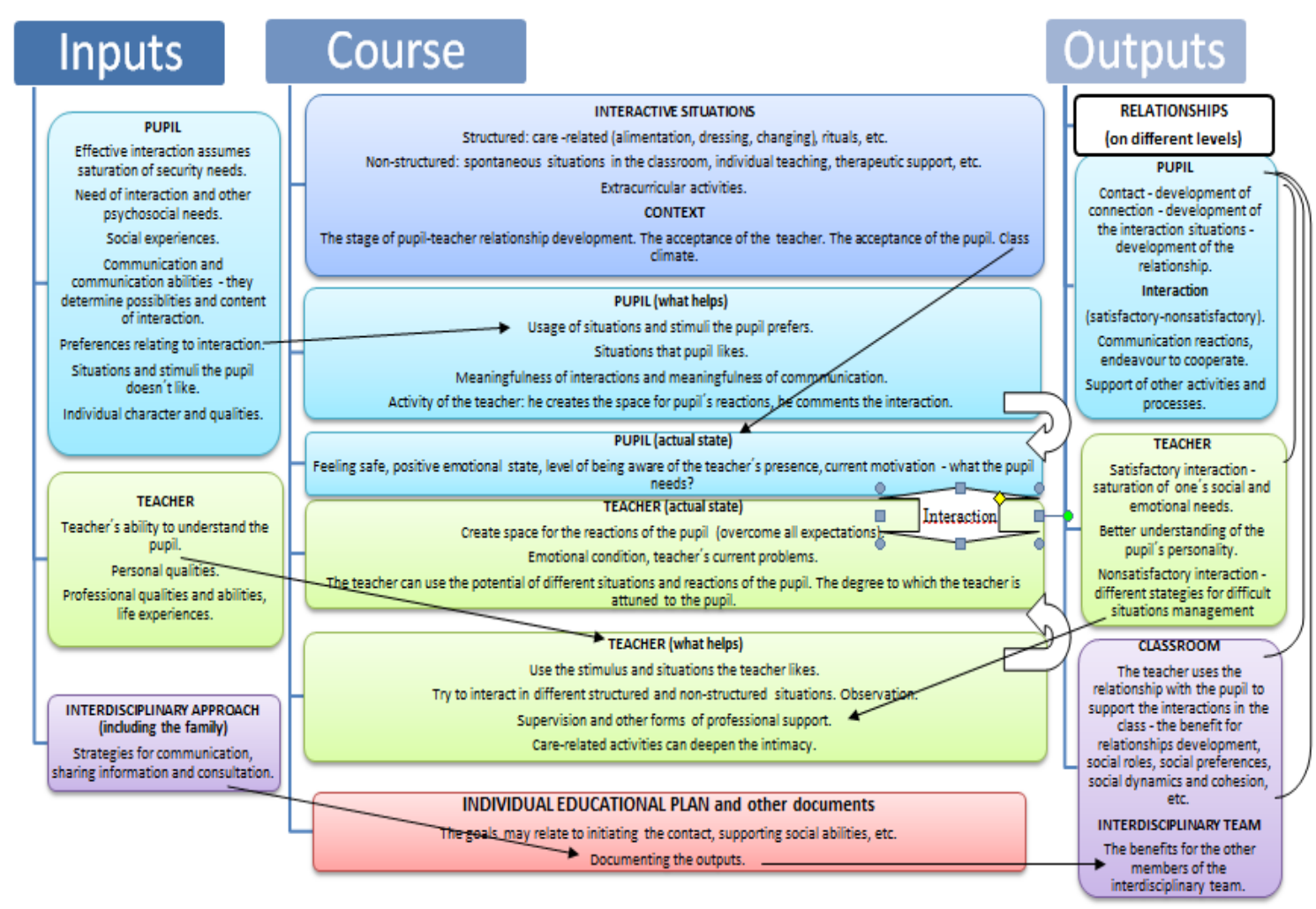

Figure 1 Interaction process model 
At this stage we also performed a critical reflection of the data obtained - the data were verified for validity by means of triangulation of data from the semistructured interviews, observations and study of educational documents. Some categories could not have been triangulated with other data sources, therefore we decided to develop a questionnaire and verify some results of the quality-based part of the research in a quantity-based way on a sample of 101 respondents. The questionnaire survey examined the educational needs of the pupils and tools to understand the pupils better. A Lickert scale was used, allowing an evaluation of truthfulness of statements on a scale from 0 to 7 (Chráska, 2007). A space was left for open responses. Most answers confirmed the conclusions of the quality-based part, only in few cases the respondents' answers caused some categories to be reconceptualised. Selected results of the questionnaire survey will be presented in the following chapter.

At the level of axial coding the categories were further reorganized and classified according to the process-based educational model as described by Průcha (2009) into inputs, course and outputs of education. We examined possible correlations between the categories in terms of the interaction process. We also performed a second order reduction and dropped the categories that appeared irrelevant in terms of the requirement of the interaction model. For the resulting model we developed a visual diagram indicating the results of the research at the level of selective coding (Figure 1). The following chapters deal with a more detailed introduction of some categories depicted in this diagram.

\section{Description of important categories at the level of educational inputs}

Input educational determinants were divided into three areas according to important subjects that take part in the interaction or influence it - pupil personality, teacher personality and rehabilitation team (including family).

Pupil personality was analysed in terms of the factors that can be significant facilitators that help initiate interaction and foster its development. The most significant was the issue of psychosocial needs, social experience, communication, preferences and personality qualities.

The obtained data on physical, mental and social needs indicate a great significance of the need for safety and higher mental needs for the interaction process. We asked the teachers what a saturated need for emotional safety means to their pupils. Their responses involved a good structure of the environment (20), requirements for a good social climate (detailed requirements to be specified below) and kind attitude of the teacher (31).

Understandably, pupils also have a need for interaction with their environment and higher mental needs (e.g. need for appreciation), similar to their intact peers. The statements of 15 teachers indicate that these pupils have a higher risk of deprivation of the need for interaction with the environment and higher mental needs. This conclusion was also confirmed by triangulating the data obtained through observation of the educational process (in some pupils we observed 
repeated excitation and activation when the teacher emerged). Moreover the interviews indicated that the teachers have less means to saturate these pupils' needs, e.g. appreciation.

During their development, pupils acquire various kinds of experience with interaction with another person. During the research we had an opportunity to analyse only those types of interaction situations that take place in the educational process (structured and unstructured situations and extra-school interactions, see below). From a methodological point of view it is difficult to assess these situations and analyse what is the influence of pupil participation on the development of his/her personality and further need for interaction. From this perspective, it was impossible to further analyse the interaction situations.

In the area of pupil communication the following categories were assessed as significant: pupils' communication responses and pupils' favourite communication topics. The pupils' communication responses were divided according to likes and dislikes into positive, negative and nonspecific. According to the types of communication signals we further distinguished motor responses (e.g. turning the head), mimic responses (e.g. frowning, smiling), voice responses (e.g. laughing, gasping), vegetative responses (e.g. changes of face skin colour), nonspecific responses and responses with a specific communication intent (e.g. rubbing the ear indicating a need to sleep). A detailed analysis of communication responses was published in a different paper (Kantor, Urbanovská, in press). The pupils' favourite communication topics included the family, shopping, sport, travelling, pets, need to share fresh experiences, selection (of food, toys), need to express a wish (change of position, request for a contact), need to describe what is happening, etc.

The pupil's preferences were divided into stimuli and situations during which the pupils express likes and those stimuli and situations during which the pupils express dislikes. The vast set of stimuli and situations during which the pupils express likes was further divided into visual stimuli, e.g. photographs or looking into a mirror (23), auditory stimuli, e.g. music or computer game sounds (31), tactile stimuli, e.g. various types of touches and surfaces such as hair or carpet (26), olfactory stimuli (6), taste stimuli (13), stimuli aimed at movement and physical experiencing, e.g. turning on a chair or swinging (16), voice and speech-related stimuli (28), situations based on verbal communication, e.g. appreciation or commenting on various situations (18), humorous situations (14), situations based on interaction, e.g. attention of other people or observing the surrounding environment (27), activities in the class or in other classes, e.g. morning circle, celebrations (25), therapeutic and stimulation activities, e.g. basal stimulation or Snoezelen (21), class-related activities, e.g. garden parties, joint music lessons (9), staying outside the school, e.g. visits to the theatre, curative stays, walks, etc. (16).

The stimuli and situations during which the pupils express dislikes are represented by interaction barriers, e.g. movement limitation (43), too strong or 
quick touch (36), strong and unexpected noise (15), unexpected position change (14), pain (4), difficult food intake (4), too many people at a time (4), situations during which the pupils are out of attention (2), fear from unknown situations, e.g. swing, animals, spoon (11), etc.

Particular attention was given to the pupils' personality. The responses of the teachers show that to a certain degree, in spite of serious functional disorders, pupils with severe multiple disability are able to manifest deep emotional life and virtues. The teachers mentioned in the interviews the following positive aspects of pupil's personality (the numbers in brackets show the number of responses): gratitude (7), strength (2), sensitivity (9), spontaneity (5), sincerity and authenticity (8), openness (2), curiosity (2), sense of accomplishment (1), enthusiasm in group activities (4), assertiveness and friendship (1). The teachers also appreciated the pupils' joyousness (5), their sense of humour (4), emotional harmony (2), their contentment with little (3), their ever-good intentions (5) and their desire to learn and gain independence (3).

In terms of the interaction process, the teacher's personality was considered from both professional and personality qualities. At the beginning of the research we identified a significant category, which is the ability to understand the pupils. Due to the fact that this category is important for the interpretation of interactions in the context of the pupils' severe functional disability and also for overall 'tuning in' to the pupil's personality, the questionnaire survey was used to verify the conclusions gained from the semi-structured interviews. The responses in this part of the research were summarized into several subcategories:

- Abilities related to establishing a relationship with another person (empathy, interest in the pupil, positive relationship with the pupil, acceptance of the pupil, etc.)

- Personality qualities (intuition, patience, calm character, flexibility, etc.)

- Professional qualities and own experience with functional disability (limitations as a result of a broken arm, not speaking during the day), ability to observe and further teacher education (courses, training, study of case studies and literature).

- Life experience - experiencing own child's development (intact as well as disabled) and experiencing motherhood.

- Team approach (including cooperation with parents and good pupil diagnostics),

- Activities in the school and out-of-school environment (particularly individual teaching, various therapies and curative stays).

Cooperation with other members of a multidisciplinary team is based on the development of mutual communication and providing various communications about the pupil, consultations in the process of developing individual educational plans, sharing observations gained during pupil diagnostics and evaluation. The significance of interdisciplinary cooperation within the 
interaction process lies for example in communicating important information that the pupil is unable to communicate, which partially compensates for the pupil's deficiencies. We revealed that almost all teachers maintain personal communication with the parents on a daily basis (35). In all cases the teachers use a diary and sometimes a telephone for communication.

\section{Course of the interaction process}

The course of the interaction process will be introduced in the context of specific situations and the degree of acceptance of the pupil and various interaction situations and factors that facilitate the interaction process.

Acceptance of the pupil is a necessary prerequisite for establishing a quality relationship (Rogers, 2014). Some partial conclusions of this research study indicate that the acceptance of a pupil with severe multiple disability can be impeded by a number of factors including particularly the pupil's incontinence (21), hypersalivation (5), physical deformities (1) and unpleasant smell, e.g. as a result of incontinence or excessive sweating (4). The teachers indicated that they try to overcome these factors by getting used to them and sharing these problems with an experienced colleague. In one case a problem with difficult acceptance was solved by reassignment of the pupil to a different class.

For effective interaction to take place the acceptance must be mutual, i.e. the pupil must also accept the teacher. The teachers expressed their views about accepting the teacher by the pupil. Some pupils have problems with adaptation to their teachers. There are two stages in the process of their relationship development. In the first stage the pupils gradually get used to the teacher with a minimum of positive emotional reactions. Only in the second stage (that can start even after several months) the pupils get actively involved in the interaction. In the interviews there were five teachers who described pupil acceptance lasting over 6 months. However, to map the stages of the development of the teacher-pupil relationship, more information is required.

In the context of the class climate the teachers gave the following characteristics: close teacher-assistant cooperation (10), use of art and pleasant stimuli, e.g. basal stimulation (11), use of humour and game (8), saturating the need for safety (7), positive internal tuning of the pupil and the teacher throughout all classes (6), etc. These requirements are in accordance with the characteristics attributed to a good climate in scientific studies on special education (Allodi, 2008).

The interaction situations were divided according to the degree of their structure to structured, unstructured and out-of-school situations. Most teacherpupil interactions take place in structured situations. As far as various structured situations are concerned, particularly all types of rituals are considered by teachers as effective for the initiation of interaction - morning circle (12), contact song and welcoming rituals (15), etc. A certain degree of structure is required for the saturation of the need for safety and orientation of the pupil. 
However, the degree of structure must allow sufficient time for the pupil's reaction. At the same time the teacher must refrain from a feeling that a specific reaction is required from the pupil and must be able to respond flexibly to the latest developments. As indicated by the teachers, some of the situations with a low degree of structure included short observations when the teacher observed the class in an uninterested way (2), spontaneous interactions during car transportation (1), resting on mattresses (3), stimulation activities (10), etc. A special group includes situations in an out-of-school environment, where the teachers have an opportunity to interact with the pupil in a different context than they are used to (16). According to the teachers, these situations are stimulating for the development of the mutual relationship, more intimate tuning in to the pupil, etc.

The process of social interaction between the teacher and the pupil corresponds with the theory of shape and countershape by A. Pesso (Pesso, Boyden-Pesso, Vrtbovská, 2009). In the context of social interaction, shape and countershape can, metaphorically speaking, fit to various degrees. The pupil and the teacher can interpret social interaction (fitting a shape and countershape) in the same or different way. For example the teacher can evaluate social interaction as meaningful (shape and countershape fit), whereas to the pupil the social interaction might make no sense (shape and countershape do not fit). On the contrary, we can speak of situations in which the interaction is favourable for the pupil but the teacher, according to various factors, e.g. own uncertainty, evaluates the interaction in an opposite way.

A specific feature of the interaction process between the teacher and the pupil with severe multiple disability is a considerable difficulty to interpret the interaction situations with respect to the strongly limited response possibilities of these pupils. As a result of their limitations, the pupils cannot develop meaningful interaction countershapes that would be generally comprehensible. Their communication responses can be specifically influenced by mental retardation, involuntary movements, spasms in the area of orofacial motor functions, inadequate co-verbal expressions, etc. In this case the interaction process is interfered by a number of communication noises. The teacher is forced respond to the difficult-to-understand communication signals of the pupil, often without any feedback confirming the correctness of the teacher's interpretation. In this way, a number of misunderstandings can occur in the communication. At present the teachers unfortunately lack adequate support in addressing these interaction issues although interpreting the interaction situations were identified as frequent difficulties encountered in their work (mentioned by 17 teachers during interviews).

Other significant factors on the part of the pupil that influence the interaction process include the pupil's emotional condition, level of perceiving the other person, level of saturation of the feeling of safety and current motivation. On the part of the teacher the interaction process is affected by the emotional condition, 
ability to provide a space for the pupil's reaction (the teacher must refrain from actually wanting something), level of tuning in to the pupil and ability to use the potential of various situations (e.g. in care-related situations such as feeding or changing the diapers can provide a high degree of tuning in, however, these situations can be carried out purely mechanically).

The process of interaction is further facilitated by:

- Use of stimuli and situations preferred by the teachers and the pupils,

- Exploitation of the pupil's positive personal qualities (e.g. during appreciation and validation of the pupil's personality),

- Support of meaningfulness and comprehensibility of communication for the pupil, e.g. by means of accompanying gestures or distinctive mimics.

- Commenting on situations - the teachers can for example comment on a situation from the pupil's viewpoint, which compensates for the pupil's missing verbal reactions and supports continued interaction,

- Ability of the teacher to observe the pupil, especially minor differences in non-verbal communications with respect to the interaction context,

- Possibility of the teacher to get support in difficult situations, whether it be supervision, colleague support or emphatic support outside work.

One of the factors influencing the success of the interaction process is the ability to connect with the pupil, which is enabled by respecting a different pace of the pupil and synchronizing with the pupil's pace. The ability to connect with the pupil creates a space for reciprocal communication, i.e. interaction synchrony at a non-verbal level, which requires the teacher's sensitivity to the timing and quality of emotional signals. This process includes emotional information transferred by means of voice quality regulated by pitch (frequency) elements and speech dynamics and is related to rhythmical connection. In the context of interaction with pupils with severe multiple disability it is therefore of vital importance to consider their specific pace which is significantly slower than in usual communication and requires patience, delays in waiting for responses, etc. on the part of the communication partner.

\section{Outcomes and documentation of the whole process}

During an analysis of educational documents we revealed that the educational objectives and outcomes in the area of interaction are not adequately documented. During an analysis of 30 individual educational plans the objectives relating to interaction included mainly the following:

- Intellectual areas - knowing the classmates and the teachers (11), identifying people in the room (5).

- Speech education - responding to an adult's voice and intonation (9),

- Social and communication skills - training of greeting and thanking (5), expressing agreement and disagreement (6), communicating needs and 
wishes (10), motivating to expressing speech (2), stimulating eye contact (12), giving a hand (2).

- Music and PE - involvement in music and physical activities of an interaction nature (11).

- Other statements relating to social interaction - supporting feelings of safety by commenting, initial touch, etc. (10), encouraging involvement in team activities (3), inducing situations leading to satisfaction (3), getting acquainted with classmates and teachers (2), supporting interaction among classmates (2).

During an analysis of observation of the educational process we noticed that the teachers pay considerable attention to the initiation and development of mutually pleasant interaction (during an analysis of some video recordings of individual teaching sessions the teacher allocated to this type of interaction as much as $70 \%$ of total time). In all video recordings we could observe good timing, sensitivity and intuitiveness of the teacher during interaction. However, during the interviews the teachers had difficulties knowingly explain how the interaction takes place.

A similarly unsatisfactory situation was observed during an analysis of 30 verbal evaluations of the pupils. The following outcomes were based on interaction:

- $\quad$ Addressing the pupil and saying goodbye (10).

- $\quad$ Other communication statements (10).

- Emotional expression during communication with people (13).

- Pupil's effort to cooperate in educational activities (10).

We believe there is a great potential for further amendments and additions in the area of documenting the objectives and outcomes of the interaction process. We need to think about some possibilities that could enrich the documentation of the educational process with meaningful outcomes in the area of interaction.

In the context of the development of the interaction process the following stages were described in terms of the pupil: contact initiation - development of the connection - development of the interaction situation - development of the relationship. To a large extent, the assessment of the connection and mutual relationship is based on subjective feelings of the teacher. Currently the teachers lack appropriate methodology that could be used for the evaluation of the connection and development of the relationship with pupils with severe multiple disability. However, in developing a contact and describing various interaction situations, teachers can use the description of stimuli significant for the development of interaction and specific situations in which interaction successfully took place.

Moreover, interaction also supports other processes that take place during education. If a pupil does not want to or cannot cooperate, the teacher can examine the pupil's interaction ability in various situations and thus create a space for more effective involvement of the pupil in the educational process. A 
successful interaction with a single pupil can be used to support social cohesion, dynamics and interaction in the whole class.

The outcomes of the interaction process also present benefits (and also risks) for the teacher. Through the relationship with the pupil the student can saturate own emotional needs. As a result of strong fixation to their care person and a low degree of autonomy, pupils with severe multiple disability provide ideal opportunities for the saturation of own emotional needs of the care persons. Although this is a legitimate profit provided to the teachers by the nature of the work and motivating the teachers to carry out this demanding profession, in some cases this can present a barrier to the development of an authentic pupilteacher relationship (especially if this mutual profit becomes an addiction and the teacher starts to restrict the choices of the pupil). The risk of transmission mechanisms is their non-deliberate occurrence and difficult recognition in a professional relationship, particularly if the perspective of one person is not available (Bruscia, 1998). The benefit of the interaction for the teacher is not documented but it must be reflected on and professional support must be searched for if needed.

\section{Conclusion}

The interaction process between the teacher and a pupil with severe multiple disability provides a number of opportunities for further research and changes in practical applications. In the preparation of pupils it is useful to discuss important categories in the context of interaction, learn to reflect on own interpretations of interactions as well as on the development of the teacher-pupil relationship. In future it will be necessary to produce strategies for description of effective teacher-student interaction. Evaluation of short-term as well as longterm outcomes of the interaction process could enrich the documentation in a meaningful way.

\section{References}

1. Allodi, M. (2008). Goals and values in school. In Social Psychology of Education. 2008 (13), pp. 207-235.

2. Bruscia, K. (1998). The Dynamics of Music Psychotherapy. ( $1^{\text {st }}$ ed.). Gilsum: Barcelona Publishers.

3. Hrebeňárová, L. (2012). Vzdelávanie žiakov s t’ažkým a hlbokým mentálnym postihnutím na Slovensku. In: Pančocha, K. et al. Životni dráha jedince v inkluzivním prostředí. $\left(1^{\text {st }}\right.$ ed.). Brno: Masarykova univerzita.

4. Chráska, M. (2007). Metody pedagogického výzkumu. Základy kvantitativního výzkumu. $\left(1^{\text {st }}\right.$ ed.). Praha: Grada.

5. Kantor, J. - Urbanovská, E. (in press). Communication in Students with Severe Cerebral Palsy. In Journal of Exceptional People. 2014, 1 (4).

6. Michalík, J. et al. (2012) Pohledy na inkluzivní vzdělávání zdravotně postižených. (1 ${ }^{\text {st }}$ ed.) 
7. Pesso, A. - Pesso-Boyden, D. - Vrtbovská, D. (2009). Úvod do Pesso Boyden System Psychomotor. ( $1^{\text {st }}$ ed.). Praha: Scan.

8. Průcha, J. (2009). Moderní pedagogika. (4 ${ }^{\text {st }}$ ed.). Praha: Portál.

9. Rogers, C. (2014). Způsob bytí. (4 ${ }^{\mathrm{st}}$ ed.). Praha: Portál.

10. Strauss, A. - Corbinová, J. (1999). Základy kvalitativního výzkumu: postupy a techniky metody zakotvené teorie. ( $1^{\text {st }}$ ed.). Boskovice: Albert.

11. Valenta, M. \& Michalík, J. - Lečbych, M. (2012). Mentální postižení v pedagogickém, psychologickém a sociálně-právním kontextu. ( $1^{\text {st }} \mathrm{ed}$.). Praha: Grada.

Jiř́ Kantor

Libuše Ludíková

Miluše Hutyrová

Pavel Svoboda
Czech Republic, Institute of Special Education Studies, Faculty of Education, Palacky University, Žižkovo nám. 5, Olomouc, 77400

Email: jirik.kantor@centrum.cz

Czech Republic, Institute of Special Education Studies, Faculty of Education, Palacky University, Žižkovo nám. 5, Olomouc, 77400

Czech Republic, Institute of Special Education Studies, Faculty of Education, Palacky University, Žižkovo nám. 5, Olomouc, 77400

Czech Republic, Institute of Special Education Studies, Faculty of Education, Palacky University, Žižkovo nám. 5, Olomouc, 77400 